\title{
Pengaruh Kecepatan Alir Udara dan Temperatur Terhadap Perpindahan Massa Padat dan Gas (Disk Naftalen-Udara) Dalam Sistem Kolom Akrilik
}

\author{
Hadyan Hilman Radifan, Lindawati \\ Program Studi Teknik Kimia, Fakultas Teknik, Universitas Surya Tangerang, Banten \\ Email: hilmanradifan23@gmail.com
}

\begin{abstract}
ABSTRAK
Perpindahan massa merupakan salah satu fundamental penting yang harus dikuasai oleh seorang sarjana teknik kimia. Sublimasi, adsorbsi, serta pengeringan merupakan salah satu contoh penerapan dari perpindahan massa padat-dan gas di bidang Industri. Tujuan dari penelitian ini adalah untuk mengetahui pengaruh temperatur dan kecepatan udara terhadap koefisien perpindahan massa padat gas (sistem disk naftalen - udara) dalam sebuah kolom akrilik silinder. Penelitian dilakukan dengan metode observasi. Variasi yang digunakan untuk temperatur adalah 318K; 330K dan $348 \mathrm{~K}$ dan untuk kecepatan alir udara adalah $1,840 \mathrm{~m} / \mathrm{s} ; 3,620 \mathrm{~m} / \mathrm{s}$; dan $4,980 \mathrm{~m} / \mathrm{s}$. Hasil observasi menunjukkan bahwa peningkatan kecepatan udara dan suhu yang masuk ke dalam sistem kolom akan menyebabkan peningkatan nilai terhadap koefisien perpindahan massa padat-gas $\left(K_{G}\right)$.
\end{abstract}

Kata kunci: Perpindahan Massa, Padat-Gas, Temperatur, Kecepatan Udara

\begin{abstract}
Mass transfer is one of the fundamental knowledge that must be mastered by a bachelor in chemical engineering. Sublimation, adsorption, and drying are examples of the application of solid-gas mass transfer in the industrial fields. The purpose of this study was to determine the effect of temperature and air velocity on the coefficient of solid - gas mass transfer (disc naphthalene-air system) in a cylindrical acrylic column. The air flow temperature used are $318 \mathrm{~K} ; 330 \mathrm{~K}$ and $348 \mathrm{~K}$ with the air velocity of $1,840 \mathrm{~m} / \mathrm{s} ; 3,620 \mathrm{~m} / \mathrm{s}$; and $4,980 \mathrm{~m} / \mathrm{s}$. The research was done by observation method. The observation results show that the increase of air velocity and temperature entering the column system will cause the increase of value to the solid-gas mass transfer coefficient $\left(K_{G}\right)$
\end{abstract}

Keywords: Mass Transfer, Solid-Gas, Temperature, Air Velocity 


\section{PENDAHULUAN}

Ketika sebuah materi memiliki konsentrasi yang lebih tinggi pada sebuah sistem maka materi tersebut akan memiliki kecenderungan untuk berpindah ke sistem lain yang memiliki konsentrasi lebih rendah. Fenomena ini disebut dengan fenomena difusi. Difusi merupakan fenomena perpindahan massa yang sering atau umum ditemui dalam kehidupan sehari-hari. Fenomena perpindahan massa sendiri merupakan sebuah fenomena yang bersifat aplikatif dan memiliki peranan penting di seluruh proses industri.

Selain diaplikasikan pada proses industri, perpindahan massa sendiri sering kita temukan dalam kehidupan sehari-hari salah satunya adalah penggunaan kapur barus untuk menghilangkan bau apek dan jamur dalam ruangan. Naftalena yang semula terkonsentrasi pada kapur barus secara perlahan akan berpindah ke udara sehingga akan mengalami pengurangan massa sehingga akan habis sama sekali ketika seluruh kandungan naftalen yang ada pada kapur barus telah berpindah seluruhnya ke udara. Perpindahan massa jenis ini adalah salah satu contoh dari perpindahan massa pada media padat - gas yang akan menjadi topik dari penelitian ini (Treybal, 1980).

Secara spesifik, fenomena perpindahan massa (termasuk difusi naftalena dari padatan kapur barus ke udara) dapat dimodelkan secara matematis ke dalam suatu koefisien yang dikenal sebagai koefisien perpindahan massa. Beberapa penelitian telah melakukan kajian terhadap variabel-variabel yang mampu memengaruhi nilai koefisien perpindahan massa (naftalena-udara), seperti Rodriguez, dkk. (1998) dan Utgikar (2015). Kedua jurnal tersebut menghitung pengaruh massa atau diameter dari sebuah komponen terhadap koefisien perpindahan massa dari komponen naftalena. Akan tetapi berdasarkan buku Treybal (1980), selain massa ataupun geometri dari komponen terdapat faktor-faktor lain yang dapat mempengaruhi koefisien perpindahan massa dari komponen tersebut seperti kecepatan alir udara dan temperatur yang masuk dari sistem unit operasi yang digunakan dalam penelitian. Oleh karena itu pada penelitian ini penulis mencoba untuk mengetahui bagaimana pengaruh dari dua variabel tersebut yaitu kecepatan alir udara dan temperatur terhadap nilai koefisien perpindahan massa padat-gas.

Selain itu, fokus lain dari penelitian ini adalah untuk membuat sebuah design alat operasi teknik kimia yang dapat digunakan dalam pengaplikasian konsep perpindahan massa padat-gas. Di mana pada penelitian ini akan dilakukan modifikasi terhadap sebuah kolom akrilik yang telah ada sehingga sistem kolom tersebut dapat digunakan sebagai sebuah modul praktiku operasi teknik kimia yang dapat digunakan untuk mengamati fenomena perpindahan massa padat dan gasdalam suatu sistem operasi yang murah, cepat, dan aman.

\section{METODE PENELITIAN}

Alat-alat yang digunakan dalam penelitian ini adalah sebagai berikut:
1. Sistem kolom akrilik
1 unit
2. Blower
1 unit
3. Hair Dryer (Phillips)
1 unit
4. Thermocouple
1 unit
5. Anemometer
1 unit
6. Jangka Sorong
1 unit
7. Stopwatch
1 unit
8. Neraca Analitik (Kern)
1 unit 
Adapun bahan-bahan yang digunakan dalam penelitian ini adalah naftalena dengan bentuk disk merek Swallow, berwarna putih.

Metodologi penelitian yang digunakan pada penelitian ini adalah tipe eksperimental. Dalam penelitian ini eksperimen yang dilakukan bertujuan untuk mencari pengaruh dari kecepatan udara yang masuk ke dalam kolom serta temperatur udara di dalam sistem kolom terhadap nilai koefisien perpindahan massa dari sistem udara-disk naftalen menggunakan sistem kolom akrilik.

Data yang diperoleh dari penelitian ini adalah ketebalan disk naftalena per waktu (z/t), temperatur udara dalam kolom akrilik, kecepatan udara yang masuk ke dalam kolom. Berdasarkan data tersebut kemudian dihitung nilai koefisien laju perpindahan massa padat - gas (disk naftalena - udara) dengan persamaan berikut (Utgikar, 2015):

$$
K_{G}=-\frac{\rho_{A}}{2 M_{A}} \frac{R_{G} T}{P y_{A s}} \frac{d z}{d t}
$$

Di mana: nilai $y_{A S}$ diperoleh dari persamaan berikut:

$$
\mathrm{y}_{\mathrm{AS}}=\frac{\mathrm{P}^{*}}{\mathrm{P}}
$$

\section{HASIL DAN PEMBAHASAN}

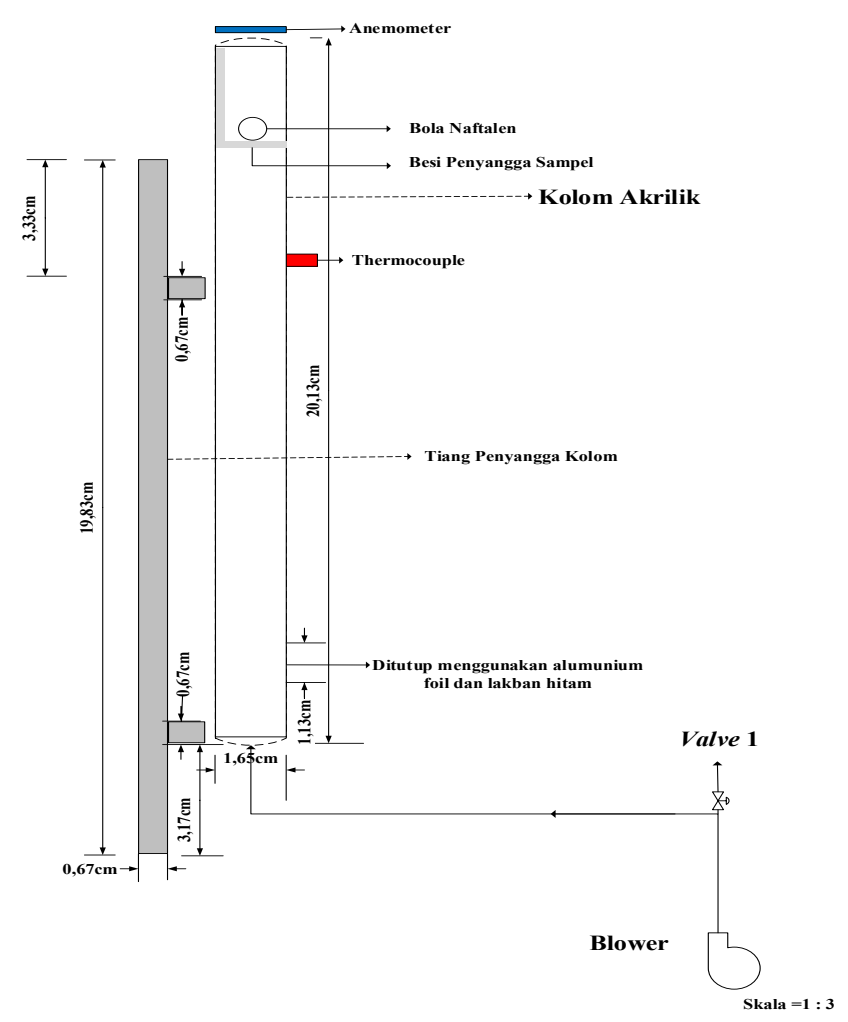

Gambar 1. Desain alat tanpa hair dryer 


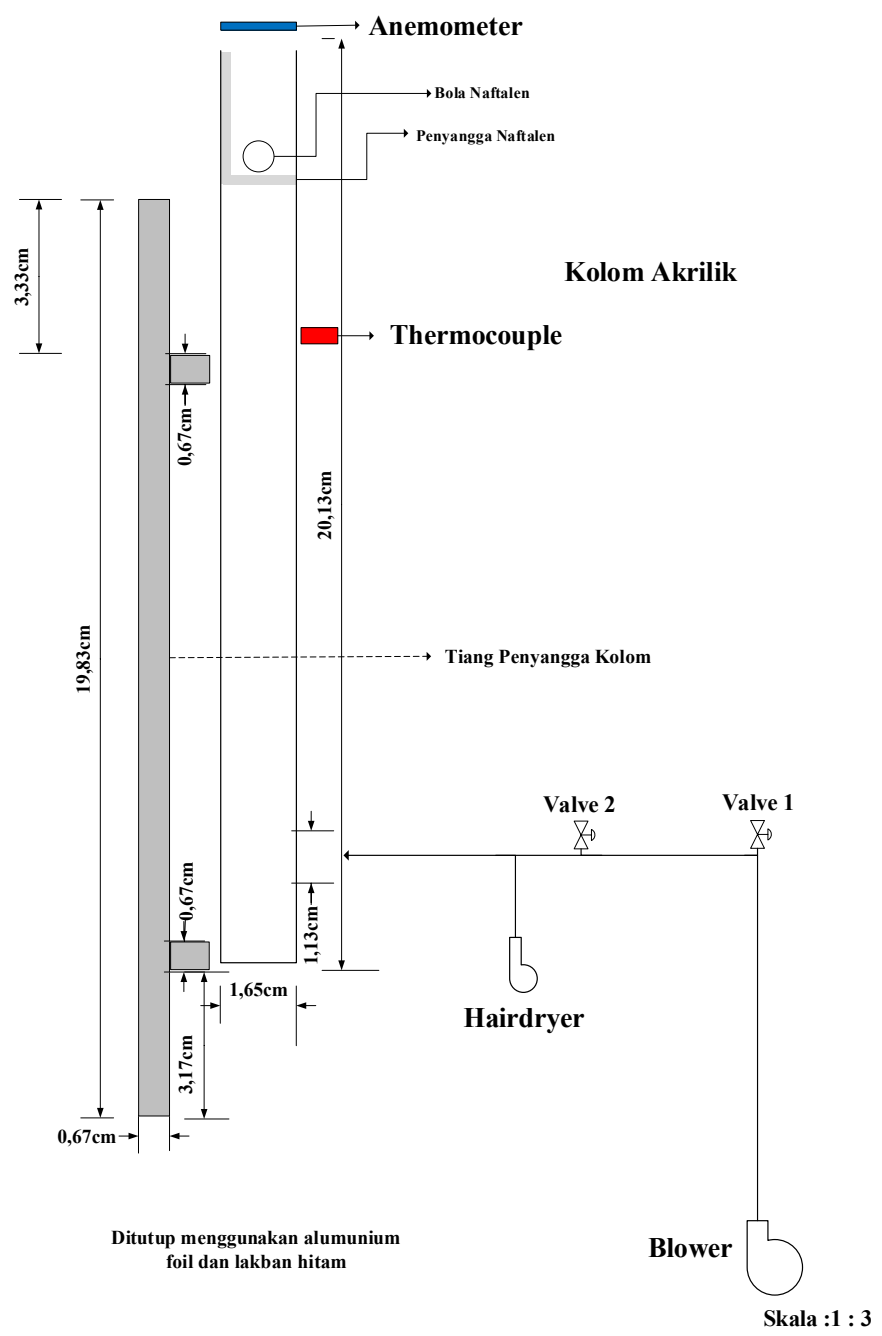

Gambar 2. Desain alat dengan hair dryer

\section{Analisis Pengaruh Kecepatan Alir Udara dan Temperatur Sistem terhadap Nilai Koefisien Perpindahan Massa Disk Naftalena-Udara}

Gambar 1 dan Gambar 2 menunjukkan konstruksi alat. Menurut Utgikar (2015), laju perpindahan massa disk naftalena dapat dijabarkan dalam persamaan berikut :

$$
2 \mathrm{~S} \mathrm{~K}_{\mathrm{G}} \mathrm{C}_{\mathrm{A}}=-\frac{\mathrm{d}(\mathrm{W})}{\mathrm{dt}}
$$

Dengan asumsi bahwa perpindahan massa dari disk naftalena terjadi pada dua circular faces dari disk naftalena (perpindahan massa pada bagian selimut silinder diabaikan), maka:

$$
\begin{gathered}
\mathrm{S}=2 \pi r^{2} \\
\mathrm{~W}=\mathrm{Sz} \frac{\rho_{\mathrm{A}}}{\mathrm{M}_{\mathrm{A}}}
\end{gathered}
$$

Sehingga:

$$
2 \mathrm{~S} \mathrm{~K}_{\mathrm{G}} \mathrm{C}_{\mathrm{A}}=-\frac{\mathrm{d}\left(\mathrm{S} \mathrm{z} \frac{\rho_{\mathrm{A}}}{\mathrm{M}_{\mathrm{A}}}\right)}{\mathrm{dt}}
$$

Nilai $\rho_{A}, M_{A}$, dan $\mathrm{S}$ adalah konstan, sehingga nilai $\mathrm{K}_{\mathrm{G}}$ dapat diperoleh melalui persaman berikut: 
Pengaruh Kecepatan Alir Udara dan Temperatur terhadap Perpindahan Massa Padat dan Gas (Disk Naftalen-

$$
\mathrm{K}_{\mathrm{G}}=-\frac{\rho_{\mathrm{A}} \mathrm{d}(\mathrm{z})}{2 M_{A} \mathrm{C}_{\mathrm{A}} \mathrm{dt}}
$$

Nilai $\mathrm{C}_{\mathrm{A}}$ dapat didefinisikan dalam persamaan berikut:

$$
\mathrm{C}_{\mathrm{A}}=\frac{\mathrm{P} y_{A S}}{R_{G} T}
$$

Subtitusi persamaan (6) ke dalam persamaan (5) maka diperoleh persamaan berikut :

$$
\mathrm{K}_{\mathrm{G}}=-\frac{\rho_{\mathrm{A}}}{2 \mathrm{M}_{\mathrm{A}}} \frac{\mathrm{R}_{\mathrm{G}} \mathrm{T}}{\mathrm{P}_{\mathrm{As}}} \frac{\mathrm{dz}}{\mathrm{dt}}
$$

Persamaan (7) akan digunakan untuk memperoleh nilai koefisien perpindahan massa melalui Gambar 3, Gambar 4 dan Gambar 5 berikut ini :

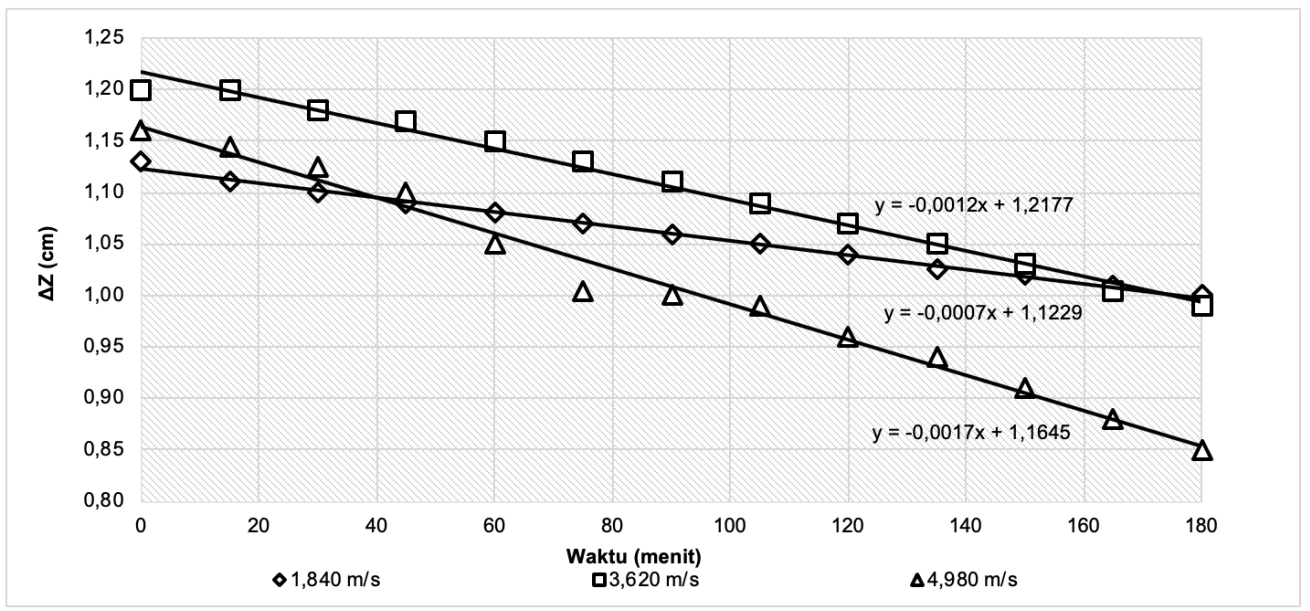

Gambar 3. Garfik penurunan Ketebalan Disk Naftalena pada Temperatur Udara $318 \mathrm{~K}$

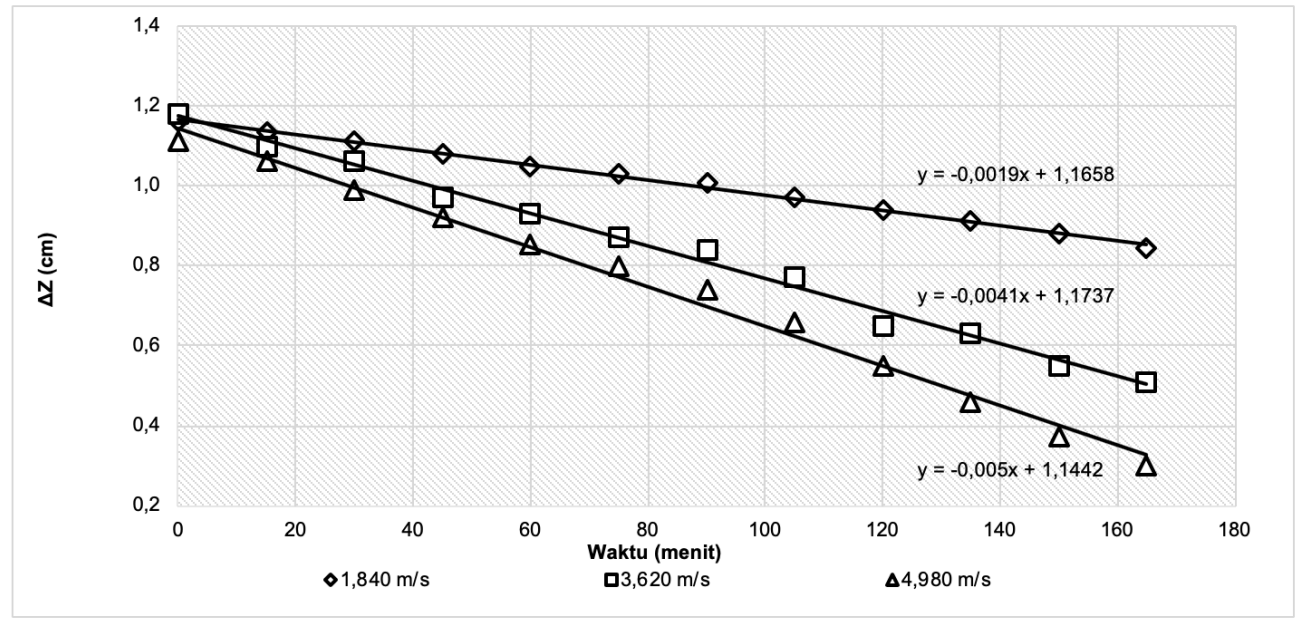

Gambar 4. Grafik Penurunan Ketebalan Disk Naftalena pada Temperatur Udara $330 \mathrm{~K}$ 


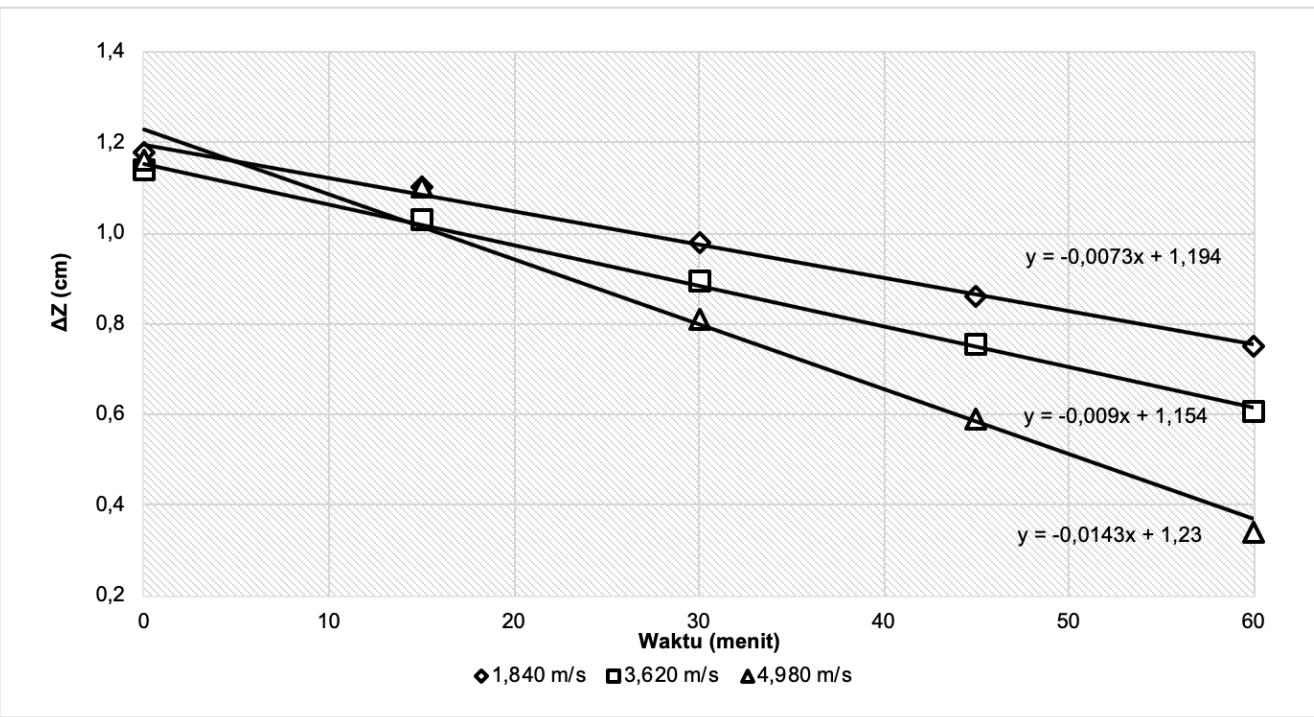

Gambar 5. Penurunan Ketebalan Disk Naftalena pada Temperatur Udara 348K

Tabel 1. Nilai Koefisien Perpindahan Massa Naftalena-Udara, $K_{G}$

\begin{tabular}{cccc}
\hline \multirow{2}{*}{ Kecepatan Udara $(\mathbf{m} / \mathbf{s})$} & \multicolumn{3}{c}{$\mathbf{K}_{\mathbf{G}} \mathbf{( \mathbf { m } / \mathbf { s } )}$} \\
\cline { 2 - 4 } & $\mathbf{T}=\mathbf{3 1 8} \mathbf{K}$ & $\mathbf{T}=\mathbf{3 3 0} \mathbf{K}$ & $\mathbf{T}=\mathbf{3 4 8} \mathbf{~}$ \\
\hline 1,840 & 0,0020 & 0,0054 & 0,0206 \\
\hline 3,620 & 0,0035 & 0,0120 & 0,0264 \\
\hline 4,980 & 0,0052 & 0,0154 & 0,0441 \\
\hline
\end{tabular}

Berdasarkan Tabel 1 dapat dilihat bahwa nilai $\mathrm{K}_{\mathrm{G}}$ atau koefisien perpindahan massa padat-gas naftalena-udara akan dipengaruhi oleh harga temperatur udara dan kecepatan udara yang masuk ke dalam sistem kolom. Nilai koefisien perpindahan massa padat-gas meningkat seiring dengan meningkatnya kecepatan alir udara serta kenaikan temperatur udara dalam kolom. Efek kenaikan temperatur pada nilai $\mathrm{K}_{\mathrm{G}}$ lebih besar dibandingkan dengan kenaikan kecepatan aliran udara kolom. Hasil serupa diperoleh dari penelitian Curteanu, dkk (2014) yang menyatakan bahwa laju sublimasi (bola) naftalena di udara kurang dipengaruhi oleh perubahan laju alir udara dibandingkan perubahan kenaikan temperatur udara.

Kecenderungan yang diperoleh pada penelitian ini membuktikan kebenaran landasan teori yang menjadi acuan dari peneliti mengenai variabel yang mempengaruhi nilai $\mathrm{K}_{\mathrm{G}}$ berdasarkan persamaan bilangan Sherwood, dan hubungannya dengan bilangan Reynolds dan bilangan Schmidt:

$$
\begin{aligned}
& S_{h}=K_{G} R T \frac{D_{p}}{D_{A B}} \\
& \mathrm{~S}_{\mathrm{h}}=\alpha \operatorname{Re}^{\mathrm{b}} \mathrm{Sc}^{\mathrm{c}}
\end{aligned}
$$

Nilai bilangan Reynolds adalah $\mathrm{Re}=\frac{\rho \mathrm{D}_{\mathrm{p}} \mathrm{v}}{\mu}$, sehingga terbukti bahwa nilai $\mathrm{K}_{\mathrm{G}}$ akan berbanding lurus dengan nilai kecepatan udara pada kolom (v). Selain itu berdasarkan persamaan (7) juga membuktikan bahwa temperatur udara kolom akan meningkatkan nilai koefisien perpindahan massa padat-gas naftalena. 
Hubungan antara temperatur dengan nilai difusivitas,$D_{A B}$, dapat dilihat pada persamaan Wilke-Lee (Treybal, 1980), di mana persamaan Wilke-Lee adalah :

$$
\mathrm{D}_{\mathrm{AB}}=\frac{10^{-4}\left(1.084-0,249 \sqrt{1 / \mathrm{M}_{\mathrm{A}}+1 / \mathrm{M}_{\mathrm{B}}}\right) \mathrm{T}^{3 / 2} \sqrt{1 / \mathrm{M}_{\mathrm{A}}+1 / \mathrm{M}_{\mathrm{B}}}}{\mathrm{P}_{\mathrm{T}}\left(\mathrm{r}_{\mathrm{AB}}\right)^{2} \mathrm{f}\left(\mathrm{kT} / \varepsilon_{\mathrm{AB}}\right)}
$$

Nilai $D_{A B}$ akan berbanding lurus dengan nilai $\mathrm{K}_{\mathrm{G}}$, sehingga semakin besar nilai $\mathrm{D}_{\mathrm{AB}}$ maka nilai $\mathrm{K}_{\mathrm{G}}$ akan semakin besar.

Berdasarkan data hasil penelitian pada tabel di atas, nilai $\mathrm{K}_{\mathrm{G}}$ terbesar terjadi pada percobaan dengan kecepatan udara serta temperatur tertinggi. Sehingga berdasarkan persamaan Wilke-Lee, kenaikan temperatur akan cenderung meningkatkan nilai $\mathrm{D}_{\mathrm{AB}}$. Sehingga berdasarkan persamaan tersebut dapat dibuktikan bahwa hasil penelitian ini adalah benar.

\section{KESIMPULAN}

Pengaruh kecepatan udara dan temperatur udara terhadap nilai koefisien perpindahan massa padat gas adalah berbanding lurus sehingga semakin tinggi kecepatan udara dan temperatur udara dalam kolom, maka nilai $\mathrm{K}_{\mathrm{G}}$ akan semakin besar. Alat serta metode yang telah didesain dapat digunakan sebagai modul praktikum yang akan digunakan untuk kepentingan pembelajaran mengenai prinsip perpindahan massa padat - gas.

\section{DAFTAR PUSTAKA}

[1] Curteanu, S., Smarandoiu, M., Horoba, D., Leon, F. (2014). Naphtalene Sublimation: Experiment And Optimatisation Based On Neuro-Evolutionary Methodology. Journal of Industrial and Engineering Chemistry, Vol. 20, p:1608-1611

[2] Rodriguez, J., Hendriquez, V., Machin, A. M. (1998). A Simple Experiment For Mass Transfer. Chemical Engineering Education, Vol. 32, No. 2, p: 142-145.

[3] Treybal, R. E. (1980). Mass-Transfer Operations. $3^{\text {rd }}$ Edition. McGraw-Hill, New York.

[4] Utgikar, V. P. (2015). Facilitating Active Learning of Concepts in Transport Phenomena: Experiment With A Subliming Solid. Chemical Engineering Education, Vol. 49, No. 4, p: 215220. 